\title{
Niobiosilica Materials as Attractive Supports for Sb-V-O Catalysts
}

\author{
H. Golinska-Mazwa $\cdot$ E. Rojas $\cdot$ R. López-Medina $\cdot$ \\ M. Ziolek • M. A. Bañares • M. O. Guerrero-Pérez
}

Published online: 27 July 2012

(c) The Author(s) 2012. This article is published with open access at Springerlink.com

\begin{abstract}
Since niobium species have been described as being able to increase the catalytic properties of the $\mathrm{Sb}$ $\mathrm{V}-\mathrm{O}$ catalytic system, the main objective of the present paper is to design a non ordered-mesoporous $\mathrm{Nb}$-containing material useful to be used as a support for this kind of catalysts. Such a material has been used as support for $\mathrm{Sb}-$ $\mathrm{V}-\mathrm{O}$ active phases and the catalysts have been characterized and tested for the propane ammoxidation reaction. For comparative purposes, and in order to evaluate the role of niobium species, the study has been also performed with a support without niobium. The results have shown how the incorporation of niobium species into the support matrix with the procedure described here leads to the formation of a very promising catalytic support. The $\mathrm{Nb}$ species incorporated into the support cooperate with vanadium species of the SbVOx active phase increasing its performance for nitrile insertion into propane. Since $\mathrm{Nb}$ is a common additive that improves the catalytic behavior of different catalytic systems, the mesoporous Nb-containing support described in the present paper could be useful for other catalysts and/or catalytic processes.
\end{abstract}

H. Golinska-Mazwa · E. Rojas · R. López-Medina ·

M. A. Bañares

Catalytic Spectroscopy Laboratory, Instituto de Catálisis y

Petroleoquímica CSIC, Marie Curie 2, 9049 Madrid, Spain

H. Golinska-Mazwa · M. Ziolek $(\bowtie)$

Faculty of Chemistry, Adam Mickiewicz University,

Grunwaldzka 6, 60-780 Poznan, Poland

e-mail: ziolek@amu.edu.pl

M. O. Guerrero-Pérez ( $\square)$

Departamento de Ingeniería Química, Universidad de Málaga,

29071 Málaga, Spain

e-mail: oguerrero@uma.es
Keywords Niobiosilica Propane - Acrylonitrile · Acetonitrile $\cdot$ Ammoxidation $\cdot \mathrm{V}-\mathrm{Sb}-\mathrm{O}$ catalysts

\section{Introduction and Objectives}

$\mathrm{Sb}-\mathrm{V}-\mathrm{O}$ based catalysts are being widely studied for several selective partial oxidation processes. Although they show good performances for some processes as the selective oxidation of $\mathrm{H}_{2} \mathrm{~S}$ to elemental sulphur $[1,2]$, the selective destruction of nitrogen-containing organic volatile compounds [3], or the oxidation of isobutylene into methacrolein [4]; the processes for which they have been extensively studied, since they are highly active and selective, is for the catalytic insertion of nitrogen into propane and/or glycerol molecules in order to obtain the desired acrylonitrile molecule [5-10]. The catalytic properties of these materials during these $\mathrm{N}$-insertion processes are, in part, due to the ability of vanadium sites in $\mathrm{SbVO}_{4}$ rutile structure to activate the ammonia molecule $[11,12]$. These processes are very important since acrylonitrile is a product worldwide used to make acrylic fibbers, acrylonitrile-butadiene-styrene and styrene-acrylonitrile resins, acryl and polyacrylamides, elastomers and other interesting products. Nowadays, acrylonitrile is produced by ammoxidation of propylene on catalyst made of promoted $\mathrm{Fe}-\mathrm{Bi}-\mathrm{Ni}-\mathrm{O}$ (BP America) or promoted $\mathrm{Fe}-\mathrm{Sb}-\mathrm{O}$ (Nitto) [13, 14]. While the direct conversion of propane into acrylonitrile by the reaction with ammonia and oxygen is an alternative route to the conventional propylene ammoxidation, the interest in obtaining acrylonitrile from glycerol is to valorize this by-product from methanolysis during the production of biodiesel. In both cases, $\mathrm{Sb}-\mathrm{V}-\mathrm{O}$ catalytic system is active and selective.

Niobium has been described as a promoter for the $\mathrm{Sb}-$ $\mathrm{V}-\mathrm{O}$ catalysts since it is able to incorporate into the rutile 
$\mathrm{VSbO}_{4}$ active phase, creating vacancies and enhancing its catalytic behavior [15, 16]. But the promoting effect of niobium additive is limited depending on the synthesis method, the $\mathrm{Nb}$ content, and the $\mathrm{Sb} / \mathrm{V}$ ratio; since this effect is lost when well defined niobium-containing phases are detected. Thus, one of the main objectives of present work is to introduce niobium species to a silica matrix and generate by this way niobium species mobile enough to be incorporated to rutile phase $\left(\mathrm{SbVO}_{4}\right)$ loaded. Following this idea we have already studied ordered NbMCM-41 and $\mathrm{Nb} / \mathrm{MCM}-48$ supported with $\mathrm{V}-\mathrm{Sb}$ [17] and we have found their attractiveness in the ammoxidation processes. Thus, in present work a non-ordered porous niobiosilica material has been prepared by a simple method without the use of template [18, 19], and applied as support for the Sb-V-O catalytic system. These catalysts have been characterized and evaluated during the ammoxidation of propane, and the comparison between $\mathrm{SiO}_{2}$ and $\mathrm{NbSiOx}$ supports for vanadium-antimony phase is also discussed.

\section{Experimental}

Niobiosilica $\mathrm{NbSiOx}$ was prepared by co-precipitation (aqueous route synthesis). Aqueous solution of $\mathrm{C}_{4} \mathrm{H}_{4}$ $\mathrm{NNbO}_{9}$ [ammonium niobiate(V)oxalate hydrate-Aldrich] was gently dropped into TEOS (tetraethyl orthosilicateAldrich), previously hydrolyzed with hydrochloric acid $(0.05 \mathrm{M})$ at room temperature for ca. $60 \mathrm{~min}$. The $\mathrm{HCl} /$ TEOS molar ratio was kept constant to 4 . The amounts of $\mathrm{Nb}$ and $\mathrm{Si}$ sources were calculated for $\mathrm{Si} / \mathrm{Nb}$ ratio equal to 64. Then, aqueous ammonia solution (28 mass\%) was added dropwise to the obtained limpid solution, until complete precipitation. The solid was aged at room temperature for $24 \mathrm{~h}$, dried under vacuum at $313 \mathrm{~K}$ for $2 \mathrm{~h}$, and calcined at $823 \mathrm{~K}$ for $8 \mathrm{~h}$.

The prepared support $\mathrm{NbSiOx}$ as well as commercial $\mathrm{SiO}_{2}$ (Degussa AG D-60287) were modified by the wetness impregnation with vanadium and antimony. Various V/Sb molar ratios were applied. The procedure of modification with $\mathrm{Sb}$ and $\mathrm{V}$ included the stepwise impregnation with antimony and vanadium precursors $\left[\left(\mathrm{CH}_{3} \mathrm{COO}\right)_{3} \mathrm{Sb}\right)$ and $\mathrm{NH}_{4} \mathrm{VO}_{3}$, respectively] using $\mathrm{V} / \mathrm{Sb}$ atomic ratios of 1 or 0.5 and $\sim 25 \mathrm{wt} \%$ of $\mathrm{Sb}$. $\mathrm{NH}_{4} \mathrm{VO}_{3}$ (BDH Chemicals Ltd) was dissolved in $\mathrm{H}_{2} \mathrm{O}$ and $\left(\mathrm{CH}_{3} \mathrm{COO}\right)_{3} \mathrm{Sb}$ (Aldrich) was dissolved in tartaric acid $(0.3 \mathrm{M})$. The amounts of both solutions accounted for $25 \mathrm{wt} \%$ of $\mathrm{Sb}$ and $5 \mathrm{wt} \%$ of $\mathrm{V}$ loading giving rise to $\mathrm{V} / \mathrm{Sb}=0.5$ atomic ratio (the sample denoted $0.5 \mathrm{VSb} / \mathrm{NbSiOx}$ ) and $25 \mathrm{wt} \%$ of $\mathrm{Sb}$ and $10 \mathrm{wt} \%$ of $\mathrm{V}$ loading leading to $\mathrm{V} / \mathrm{Sb}=1$ atomic ratio (the sample denoted $1 \mathrm{VSb} / \mathrm{NbSiOx})$. The outgassed calcined mesoporous material (353 K, $1 \mathrm{~h}$ in evaporator) was filled in with the appropriate amount of tartaric acid solution of $\mathrm{Sb}$ precursor and placed in an evaporator flask, where the catalyst was rotated and heated at $353 \mathrm{~K}$ for ca $12 \mathrm{~h}$. After such drying impregnation by the admission of aqueous solution of $\mathrm{NH}_{4} \mathrm{VO}_{3}$ followed. Finally the catalyst was dried at $353 \mathrm{~K}$ for $12 \mathrm{~h}$ and calcined in air at $923 \mathrm{~K}$ for $96 \mathrm{~h}$ (the sample marked as $0.5 \mathrm{VSb} / \mathrm{NbSiOx}(923)$ or at $813 \mathrm{~K}$ for $6 \mathrm{~h}$ [the sample marked as $0.5 \mathrm{VSb} / \mathrm{NbSiOx}(813)]$. These two calcinations temperatures were chosen for the possible comparison with the studies performed earlier on mesoporous materials.

To establish the $\mathrm{Si} / \mathrm{Nb}$ or $\mathrm{Si} / \mathrm{V}$ or $\mathrm{Si} / \mathrm{Sb}$ ratio $\mathrm{X}$-ray fluorescence (XRF) was applied using MiniPal-Philips apparatus. The measurements were done using calibration curves based on the XRF measurements for the prepared mixtures from silica (Degussa) and $\mathrm{Nb}_{2} \mathrm{O}_{5}$ (Alfa Aesar) or $\mathrm{V}_{2} \mathrm{O}_{5}$ (Aldrich) or $\mathrm{Sb}_{2} \mathrm{O}_{3}$ (Aldrich) ( $\mathrm{Si} / \mathrm{V}$ or $\mathrm{Si} / \mathrm{Sb}$ from 1 to 300).

The prepared materials were characterized by XRD (D8 Advance, Bruker diffractometer) with the use of $\mathrm{Cu} \mathrm{K} \alpha$ radiation $(\lambda=0.154 \mathrm{~nm})$. The surface area and pore volume of the catalysts were estimated by nitrogen adsorption at $77 \mathrm{~K}$ using the conventional technique on a Micromeritics 2010 apparatus. Prior to the adsorption measurements, the samples were degassed in vacuum at $573 \mathrm{~K}$ for $2 \mathrm{~h}$. UV-Vis spectra were registered using a Varian-Cary 300 Scan UV-visible spectrophotometer. Catalyst powders were placed into the cell equipped with a quartz window. The Kubelka-Munk function $(\mathrm{F}(\mathrm{R}))$ was used to convert reflectance measurements into equivalent absorption spectra using the reflectance of SPECTRALON as a reference. Photoemission spectra (XPS) were collected by a VSW Scientific Instrument spectrometer, equipped with a standard Al K excitation source. The binding energy (BE) scale was calibrated by measuring $\mathrm{C} 1 s$ peak $(\mathrm{BE}=285.1 \mathrm{eV})$.

Raman spectra were run with a single monochromator Renishaw System 1000 equipped with a cooled CCD detector $(200 \mathrm{~K})$ and Edge filter. The Edge filter was used to filter off the elastic scattering, and the Raman signal remained higher than when triple monochromator spectrometers were used. The samples were excited with the $488 \mathrm{~nm}$ Ar line; spectral resolution was ca. $3 \mathrm{~cm}^{-1}$ and spectrum acquisition consisted of 10 accumulations of $30 \mathrm{~s}$. The spectra were obtained under dehydrated conditions (ca. $473 \mathrm{~K}$ ) in a hot stage (Linkam TS-1500). Hydrated samples were obtained at room temperature after and under exposure to a stream of humid synthetic air.

Gas-phase propane ammoxidation was performed using a conventional microreactor with online gas chromatograph equipped with flame ionization and thermal conductivity detectors. Tests were made using $0.1 \mathrm{~g}$ of sample with particle dimensions in the $0.25-0.125 \mathrm{~mm}$ range. The following feedstock was applied: $25 \% \mathrm{O}_{2}, 9.8 \%$ propane, $8.6 \%$ ammonia balance He. The total flow rate was $20 \mathrm{~mL} \mathrm{~min}^{-1}$. 
Yields and product selectivities were determined on the basis of moles of propane feed and products, taking into account the number of carbon atoms in each molecule.

\section{Results}

\subsection{Characterization}

Table 1 shows the texture parameters of both supports $\left(\mathrm{SiO}_{2}\right.$ and $\left.\mathrm{NbSiOx}\right)$ and $\mathrm{Sb}-\mathrm{V}-\mathrm{O}$ supported-catalysts, based on nitrogen adsorption isotherms. As expected, both the surface area and the pore volume values decrease after $\mathrm{Sb}$ and $\mathrm{V}$ oxides impregnation, being these values especially low for the catalysts with higher coverage that have been calcined at the higher temperatures [1 VSb/ $\mathrm{NbSiOx}(923)$ and $\left.1 \mathrm{VSb} / \mathrm{SiO}_{2}(923)\right]$.

XRD patterns are shown in Fig. 1. The pattern of the rutile $\mathrm{SbVO}_{4}$ phase is detected in all the catalysts (JCPDS file 16-0600); as expected, the pattern is more intense for the samples with higher coverages, especially those supported on NbSiOx. Table 1 also includes the particle size of $\mathrm{Sb}_{0.95} \mathrm{~V}_{0.95} \mathrm{O}_{4}$ calculated from XRD peaks. Two values of particle size have been calculated; the slight differences between them indicate a different distribution of crystal faces; however, the general tendency in the particle size is similar for both faces. The $(110)$ face $\left(2 \Theta=27.4^{\circ}\right)$ is more abundant than the $(211)$ phase $\left(2 \Theta=53.4^{\circ}\right)$ in all the materials studied. It is characteristic that particle size of rutile phase is higher when $\mathrm{SbVO}_{4}$ is loaded on $\mathrm{NbSiOx}$ than on $\mathrm{SiO}_{2}$. The reason for this behaviour can be the migration of $\mathrm{Nb}$ from the support to $\mathrm{SbVO}_{4}$ structure resulting in the increase of particle size.

Binding energies obtained for all the samples are listed in Table 2. The binding energies obtained for niobium in all the samples are characteristic of $\mathrm{Nb}^{5+}$ species $[20,21]$. $\mathrm{V} 2 p$ BE region typically exhibits its maximum near $517 \mathrm{eV}$; at higher coverage, the $\mathrm{V} 2 p$ signal exhibits a second component, at lower binding energy (516.1-516.5) is associated with $\mathrm{V}^{4+}$ species, associated with the presence of $\mathrm{SbVO}_{4}$ structures [22], since in the rutile $\mathrm{SbVO}_{4}$ phase, the presence of $\mathrm{V}^{5+}$ and $\mathrm{Sb}^{3+}$ has been excluded, and the presence of $\mathrm{Sb}^{5+}$ has been confirmed, along with $\mathrm{V}^{3+}$ and/or $\mathrm{V}^{4+}$, depending the conditions [12]. Thus, the presence of reduced $\mathrm{V}^{4+} / \mathrm{V}^{3+}$ species in the XPS spectra is related with the formation of $\mathrm{SbVO}_{4}$ phase, whereas $\mathrm{V}^{5+}$ is usually related with $\mathrm{V}_{2} \mathrm{O}_{5}$ and/or VOx species. Table 2 also shows the $\mathrm{Si} / \mathrm{Nb}$ and $\mathrm{Si} / \mathrm{V}$ molar ratio determined by both XPS and XRF. These indicate that the surface of NbSiOx support and catalyst series is richer in niobium than the bulk. Interestingly, the concentration of niobium species is highest on the surface of $0.5 \mathrm{VSb} / \mathrm{NbSiOx}(813)$. It means that in the case of this sample the biggest migration of

Table 1 Texture/structure parameters

\begin{tabular}{|c|c|c|c|c|c|}
\hline \multirow[t]{2}{*}{ Catalyst } & \multirow{2}{*}{$\begin{array}{l}\text { Surf. area } \\
\text { BET } \\
\left(\mathrm{m}^{2} \mathrm{~g}^{-1}\right)\end{array}$} & \multirow{2}{*}{$\begin{array}{l}\text { Pore } \\
\text { volume } \\
\text { BJH }\left(\mathrm{cm}^{3} \mathrm{~g}^{-1}\right)\end{array}$} & \multicolumn{2}{|c|}{$\mathrm{Sb}_{0.95} \mathrm{~V}_{0.95} \mathrm{O}_{4}$ size $(\mathrm{XRD})(\mathrm{nm})$} & \multirow{2}{*}{$\begin{array}{l}\text { Intensity ratio } \\
\text { peak at } 27.4 / \\
\text { peak at } 53.4\end{array}$} \\
\hline & & & $\begin{array}{l}2 \Theta=27.4 \\
(110)\end{array}$ & $\begin{array}{l}2 \Theta=53.4 \\
(211)\end{array}$ & \\
\hline $\mathrm{NbSiOx}$ & 165 & 0.9 & - & - & - \\
\hline $0.5 \mathrm{VSb} / \mathrm{NbSiOx}(923)$ & 92 & 0.3 & 40 & 28 & 1.8 \\
\hline \multicolumn{6}{|l|}{$\mathrm{Sb} / \mathrm{V} \sim 6^{*}$} \\
\hline $0.5 \mathrm{VSb} / \mathrm{NbSiOx}(813)$ & 74 & 0.3 & 44 & 36 & 1.5 \\
\hline \multicolumn{6}{|l|}{$\mathrm{Sb} / \mathrm{V}=7.8^{*}$} \\
\hline $1 \mathrm{VSb} / \mathrm{NbSiOx}(923)$ & 18 & 0.1 & 41 & 33 & 1.6 \\
\hline \multicolumn{6}{|l|}{$\mathrm{Sb} / \mathrm{V}=1.5^{*}$} \\
\hline $1 \mathrm{VSb} / \mathrm{NbSiOx}(813)$ & 54 & 0.1 & 46 & 41 & 2.0 \\
\hline \multicolumn{6}{|l|}{$\mathrm{Sb} / \mathrm{V}=1.3^{*}$} \\
\hline $\mathrm{SiO}_{2}$ & 176 & - & - & - & - \\
\hline $0.5 \mathrm{VSb} / \mathrm{SiO}_{2}(923)$ & 67 & 0.4 & 32 & 23 & 1.2 \\
\hline \multicolumn{6}{|l|}{$\mathrm{Sb} / \mathrm{V}=7.2^{*}$} \\
\hline $0.5 \mathrm{VSb} / \mathrm{SiO}_{2}(813)$ & 73 & 0.3 & 36 & 30 & 2.1 \\
\hline \multicolumn{6}{|l|}{$\mathrm{Sb} / \mathrm{V}=6.8^{*}$} \\
\hline $1 \mathrm{VSb} / \mathrm{SiO}_{2}(923)$ & 8 & 0.1 & 40 & 37 & 2.1 \\
\hline \multicolumn{6}{|l|}{$\mathrm{Sb} / \mathrm{V}=1.4^{*}$} \\
\hline $1 \mathrm{VSb} / \mathrm{SiO}_{2}(813)$ & 65 & 0.2 & 39 & 34 & 2.3 \\
\hline $\mathrm{Sb} / \mathrm{V}=1.4^{*}$ & & & & & \\
\hline
\end{tabular}

* Calculated from XRF results 
Fig. 1 XRD patterns of: a $0.5 \mathrm{VSb} / \mathrm{NbSiOx}(923)$, b $0.5 \mathrm{VSb} / \mathrm{NbSiOx}(813)$, c $1 \mathrm{VSb} / \mathrm{NbSiOx}(923), d 1 \mathrm{VSb} /$ $\mathrm{NbSiOx}(813), e$ e $0.5 \mathrm{VSb} /$ $\mathrm{SiO}_{2}(923), f 0.5 \mathrm{VSb} / \mathrm{SiO}_{2}(813)$, $g 1 \mathrm{VSb} / \mathrm{SiO}_{2}(923), h 1 \mathrm{VSb} /$ $\mathrm{SiO}_{2}(813)$

Table 2 XPS and XRF results

$B E$ binding energies

niobium species towards rutile of $\mathrm{Sb}_{0.95} \mathrm{~V}_{0.95} \mathrm{O}_{4}$ phase occurs (shift of $\mathrm{Si} / \mathrm{Nb}=25.4$ for pristine $\mathrm{NbSiOx}$ support towards $\mathrm{Si} / \mathrm{Nb}=7.6$ for $\mathrm{VSb}$ loaded sample).

The UV-Vis spectra for all the supported SbVOx catalysts are shown in Fig. 2. UV-Vis region examined is associated with the transfer of electron from oxygen to the transition metal. UV-Vis bands confirms the presence of tetrahedral $\mathrm{Nb}(\mathrm{V})$ species located in the silicate matrix (NbSiOx), which exhibit characteristic bands near 225 and $267 \mathrm{~nm}$ [23] (Fig. 2e). The band at $225 \mathrm{~nm}$ remains almost unchanged upon $\mathrm{Sb}-\mathrm{V}-\mathrm{Ox}$ addition although it is also present on the samples without niobium species. The absorption band at $267 \mathrm{~nm}$ grows stronger upon addition of $\mathrm{Sb}-\mathrm{V}-\mathrm{Ox}$. The reason is that this band overlaps with that assigned to the oxygen to tetrahedral $\mathrm{V}(\mathrm{V})$ charge transfer

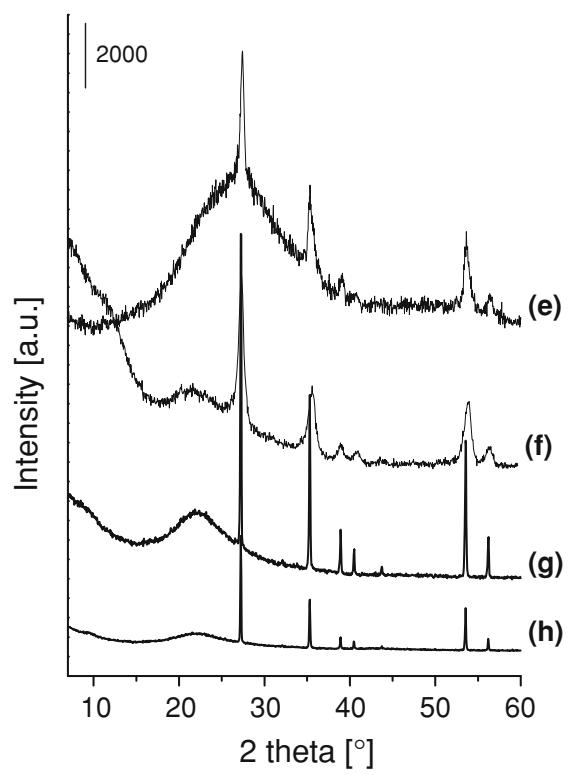

\begin{tabular}{llllll}
\hline $\mathrm{NbSiOx}$ & 208.5 & \multicolumn{1}{l}{ - } & 25.4 & 62.5 & - \\
$0.5 \mathrm{VSb} / \mathrm{NbSiOx}(923)$ & 208.9 & 517.5 & 21.6 & 62.5 & 40.0 \\
$0.5 \mathrm{VSb} / \mathrm{NbSiOx}(813)$ & 208.1 & 517.5 & 7.6 & 62.5 & 43.5 \\
$1 \mathrm{VSb} / \mathrm{NbSiOx}(923)$ & 207.0 & 517.7 & 17.4 & 62.5 & 13.9 \\
& & 516.4 & & & \\
$1 \mathrm{VSb} / \mathrm{NbSiOx}(813)$ & 207.2 & 517.0 & 13.6 & 62.5 & 13.2 \\
& & 515.8 & & & \\
$0.5 \mathrm{VSb} / \mathrm{SiO}_{2}(923)$ & - & 517.6 & - & - & 43.5 \\
$0.5 \mathrm{VSb} / \mathrm{SiO}_{2}(813)$ & - & 517.1 & - & - & 40.0 \\
$1 \mathrm{VSb} / \mathrm{SiO}_{2}(923)$ & - & 517.3 & - & & 13.7 \\
& - & 516.5 & & - & 13.3 \\
$1 \mathrm{VSb} / \mathrm{SiO}_{2}(813)$ & - & 517.6 & - & & - \\
\hline
\end{tabular}

transitions, involving bridging (V-O-Si) oxygen. A shoulder is clearly detected at about $390 \mathrm{~nm}$ for $0.5 \mathrm{VSb} /$ $\operatorname{NbSiOx}(813)$ and $1 \mathrm{VSb} / \mathrm{NbSiOx}(923)$ (Fig. 2a, d), i.e. the samples calcined at lower temperature $(813 \mathrm{~K})$ and of higher content of vanadium, respectively; it is assigned to the electron transfer from $\mathrm{V}(\mathrm{V})$ to terminal $(\mathrm{V}=\mathrm{O})$ oxygen. The UV-Vis band at the same position $(362 \mathrm{~nm})$ is very intense for rutile $\mathrm{Sb}_{0.95} \mathrm{~V}_{0.95} \mathrm{O}_{4}$ [17]. In the spectrum of $1 \mathrm{VSb} / \mathrm{SiO}_{2}(923)$ (Fig. 2i) this band shifts to $385 \mathrm{~nm}$. Moreover, it should be emphasized that $\mathrm{NbSiOx}$ series calcined at $923 \mathrm{~K}$ exhibit the profiles octahedrally coordinated $\mathrm{V}_{2} \mathrm{O}_{5}$ at ca. $360 \mathrm{~nm}$ (Fig. 2c, d).

Figure 3 shows the Raman spectra of fresh and used samples. The shape of the spectra of samples with and without niobium is quite different, indicative that the effect 
Fig. 2 UV-Vis spectra of: a $0.5 \mathrm{VSb} / \mathrm{NbSiOx}(813)$, b $1 \mathrm{VSb} / \mathrm{NbSiOx}(813)$, c $0.5 \mathrm{VSb} / \mathrm{NbSiOx}(923)$, $d 1 \mathrm{VSb} / \mathrm{NbSiOx}(923)$, $e \mathrm{NbSiOx}, f 0.5 \mathrm{VSb} / \mathrm{SiO}_{2}(923)$, g $0.5 \mathrm{VSb} / \mathrm{SiO}_{2}(813), h 1 \mathrm{VSb} /$ $\mathrm{SiO}_{2}(813), i 1 \mathrm{VSb} / \mathrm{SiO}_{2}(923)$

Fig. 3 Raman spectra at $473 \mathrm{~K}$ for fresh (F) and used (U) catalysts
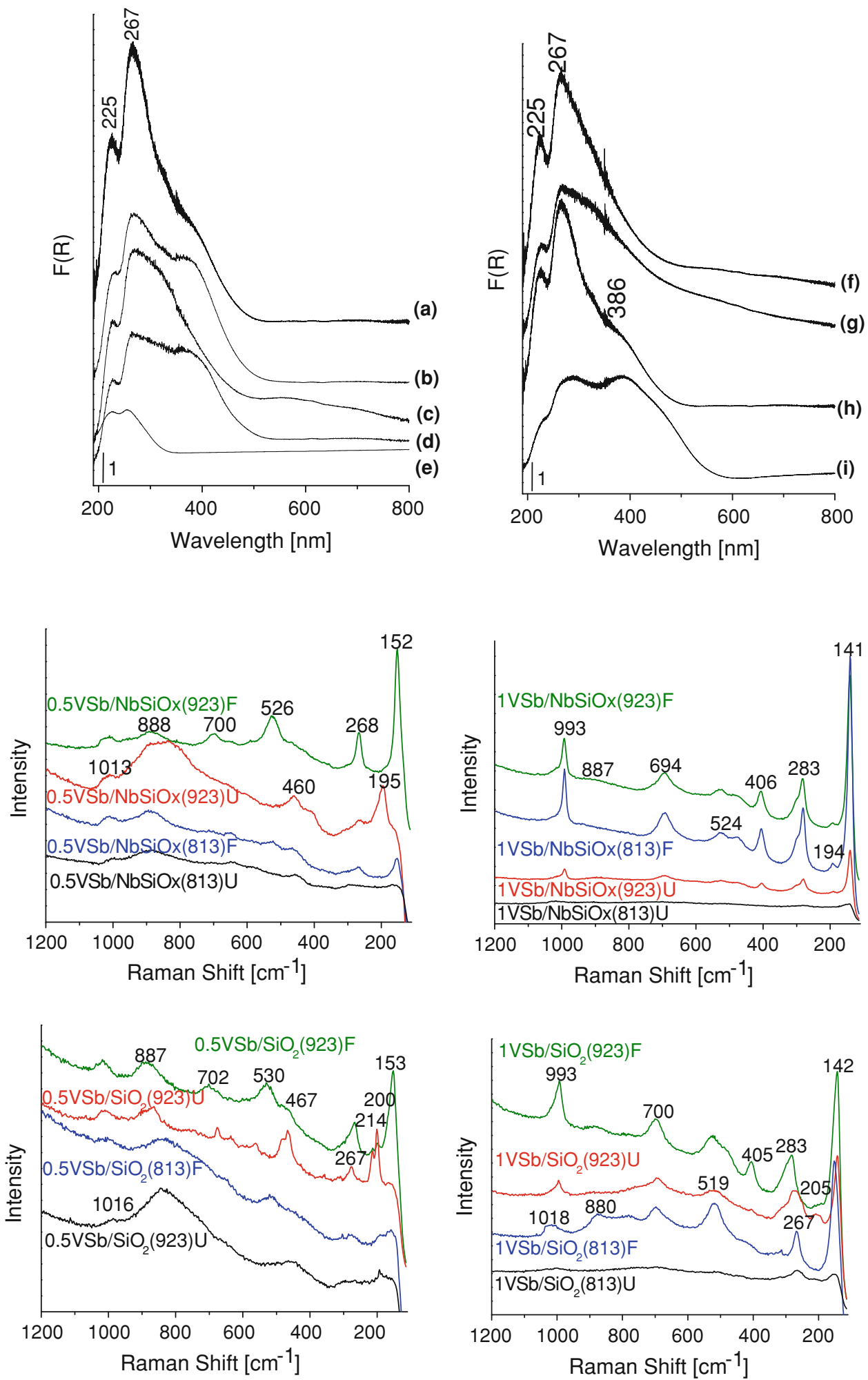

that a small amount of $\mathrm{Nb}$ induces in the structure of the $\mathrm{Sb}-\mathrm{V}-\mathrm{O}$ catalysts. Fresh $0.5 \mathrm{VSb} / \mathrm{NbSiOx}(923)$ exhibits a broad Raman band near $880 \mathrm{~cm}^{-1}$, characteristic of supported $\mathrm{Sb}_{0.95} \mathrm{~V}_{0.95} \mathrm{O}_{4}$ rutile phase [7] and $\mathrm{V}-\mathrm{Nb}-\mathrm{O}$ mixed phases [15]. Such $\mathrm{V}-\mathrm{Nb}-\mathrm{O}$ vibrations correspond to interactions between these cations, due to the incorporation of $\mathrm{Nb}$ species into the $\mathrm{SbVO}_{4}$ lattice, creating defects and vacancies. Raman bands at 190 and $259 \mathrm{~cm}^{-1}$ evidence the presence of $\mathrm{Sb}_{2} \mathrm{O}_{4}$ oxide [6], which most intense band is that at $190 \mathrm{~cm}^{-1}$, in the fresh sample. The bands near 152 and 268 corresponds to $\mathrm{Sb}_{2} \mathrm{O}_{3}$ oxide, whereas the bands near 190 and 259 correspond to $\mathrm{Sb}_{2} \mathrm{O}_{4}$, thus, $\mathrm{Sb}$ (III) 

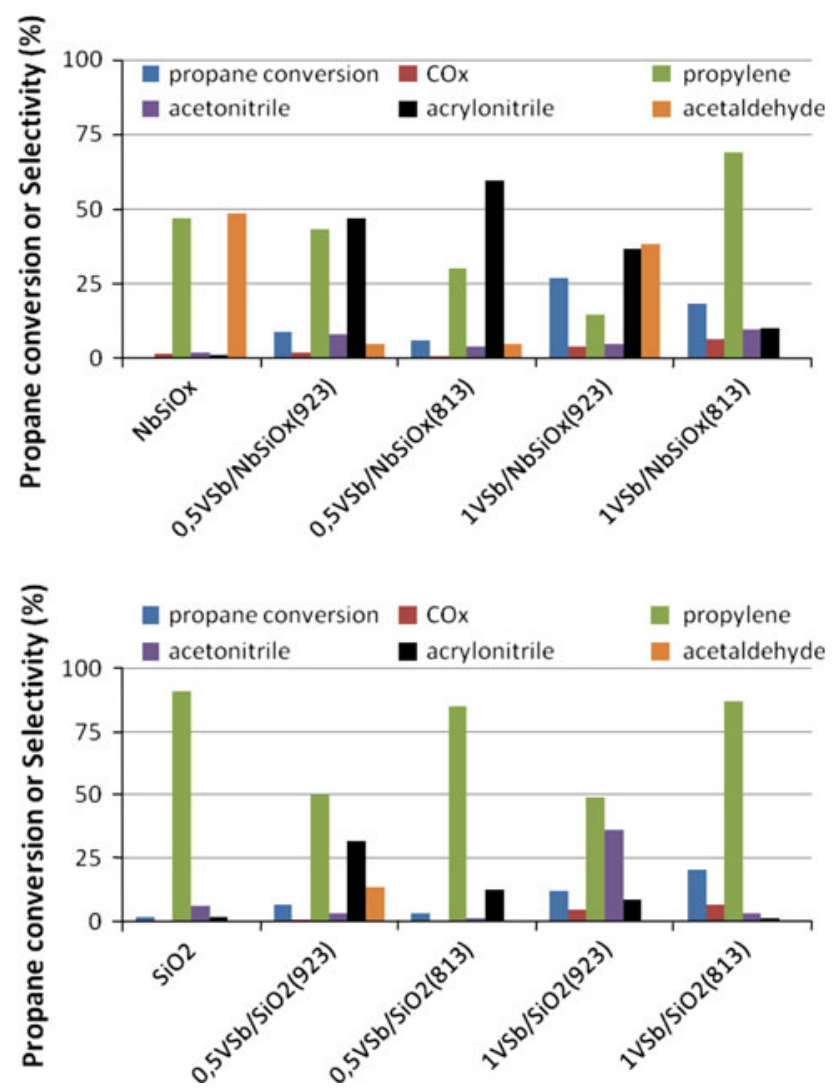

Fig. 4 Propane conversion (\%) and selectivity to main products (\%) obtained during the propane ammoxidation reaction at $773 \mathrm{~K}$. Reaction conditions: total flow $20 \mathrm{~cm}^{3} \mathrm{~min}^{-1}$; feed composition (\% volume): $\mathrm{C}_{3} \mathrm{H}_{8} / \mathrm{O}_{2} / \mathrm{NH}_{3} / \mathrm{He}(9.8 / 25 / 8.6 / 56.6), 100 \mathrm{mg}$ of catalysts

partially oxidizes under reaction conditions, since $\mathrm{Sb}(\mathrm{V})$ and $\mathrm{Sb}(\mathrm{III})$ are present in $\mathrm{Sb}_{2} \mathrm{O}_{4}$ oxide [7]. The Raman band at the $1010-1020 \mathrm{~cm}^{-1}$ range is assigned to the terminal $\mathrm{V}=\mathrm{O}$ bond of dispersed VOx structures [24]. The Raman spectra for the corresponding sample calcined at lower temperature, $0.5 \mathrm{VSb} / \mathrm{NbSiOx}(813)$, is similar but it does not exhibit the $\mathrm{Sb}_{2} \mathrm{O}_{4}$ bands. Alternatively, it possesses weak bands near 650,450 and $294 \mathrm{~cm}^{-1}$ that are assigned to amorphous SbOx phase supported on silicamesoporous materials [17]. A similar scenario is observed in the absence of niobium [samples $0.5 \mathrm{VSb} / \mathrm{SiO}_{2}(923)$ and (813)], since the presence of $\mathrm{Sb}_{2} \mathrm{O}_{4}$ is detected in the sample calcined at higher temperature, and a new peak near $255 \mathrm{~cm}^{-1}$ becomes apparent for $0.5 \mathrm{VSb} / \mathrm{SiO}_{2}(923)$, which is assigned to $\mathrm{Sb}_{2} \mathrm{O}_{3}$ [6]. The signal in the 450-470 range, visible in the samples without niobium, is characteristic of $\mathrm{Si}-\mathrm{O}-\mathrm{Si}$ stretching vibration of the support [25]. The Raman spectra of the samples with higher vanadium content do not show the bands corresponding to amorphous SbOx oxides and are dominated by the signals corresponding to $\mathrm{V}_{2} \mathrm{O}_{5}$ oxide; that presents Raman bands at 145 , 283, 405, 480, 526, 698, and $994 \mathrm{~cm}^{-1}$ [6]. Since such oxide was not detected by XRD (Fig. 2), it confirms that it is present at a nanoscaled particle, most likely smaller than $4 \mathrm{~nm}$. These bands are less intense in the used samples, indicative that the $\mathrm{V}_{2} \mathrm{O}_{5}$ phase tends to disaggregated during ammoxidation reaction.

\subsection{Activity Measurements}

Figure 4 shows the propane conversion and the selectivity to main products obtained during the propane ammoxidation reaction. The supports $\left(\mathrm{NbSiOx}\right.$ and $\left.\mathrm{SiO}_{2}\right)$ are not selective for nitrogen insertion; thus, $\mathrm{Sb}-\mathrm{V}-\mathrm{O}$ phases are required for ammoxidation. The incorporation of $\mathrm{Nb}$ into the silica matrix, with the subsequent generation of acid sites, increases the selectivity to cracking products, acetonitrile, acetaldehyde and COx. For all the $\mathrm{Sb}-\mathrm{V}$ catalysts, the selectivity to acrylonitrile increases with the use of the $\mathrm{Nb}$-containing support, being higher for the catalysts with lower coverages; in particular, $0.5 \mathrm{VSb} / \mathrm{NbSiOx}(813)$ affords the highest acrylonitrile selectivity.

Figures 5 and 6 shows the selectivity or conversion profiles versus temperature for the samples selective to acrylonitrile formation. The samples with antimony excess exhibit propylene the main product at low temperatures. Acrylonitrile becomes the main product for the Nb-containing catalysts at higher temperatures. Similar profiles have been described for $\mathrm{Sb}-\mathrm{V}-\mathrm{O}$ catalysts [26], which confirm that propylene is the main reaction intermediate during this reaction. The catalysts that possess $\mathrm{V}_{2} \mathrm{O}_{5}$, as identified by Raman spectroscopy (Fig. 3), are selective to propylene and acetonitrile (Fig. 4), which indicates that in this case the intermediate propylene cracks into the $\mathrm{C}_{2}$ product.

\section{Discussion}

\subsection{Role of Sb Species}

The calcination temperature strongly affects antimony species. In the case of catalysts with excess of antimony, the higher temperature of calcination leads to the formation of crystalline $\mathrm{Sb}_{2} \mathrm{O}_{4}$ as confirmed by Raman spectroscopy (Fig. 3), whereas amorphous SbOx species are present in the case of the catalysts prepared at lower calcination temperatures. It has been demonstrated that the active sites of these materials are the vanadium species, but the vicinity of antimony sites is required in order to provide the adequate local environment for the insertion of the nitrile into the propylene intermediate [11]; thus, the nature of antimony species is critical for these materials. This fact is also confirmed in present paper since acrylonitrile is obtained as main product only for catalysts with high $\mathrm{Sb}$ excess $(\mathrm{Sb} / \mathrm{V}$ $\geq 6$ ). Thus, the catalyst that performs better is $0.5 \mathrm{VSb} /$ 
Fig. 5 Propane conversion (square) and selectivity to propene (circle), acetonitrile (triangle), acrylonitrile (inverted triangle) and acetaldehyde (diamond) for catalysts with $\mathrm{V} / \mathrm{Sb}=0.5$ (at various temperatures in the range $623-773 \mathrm{~K}$ )
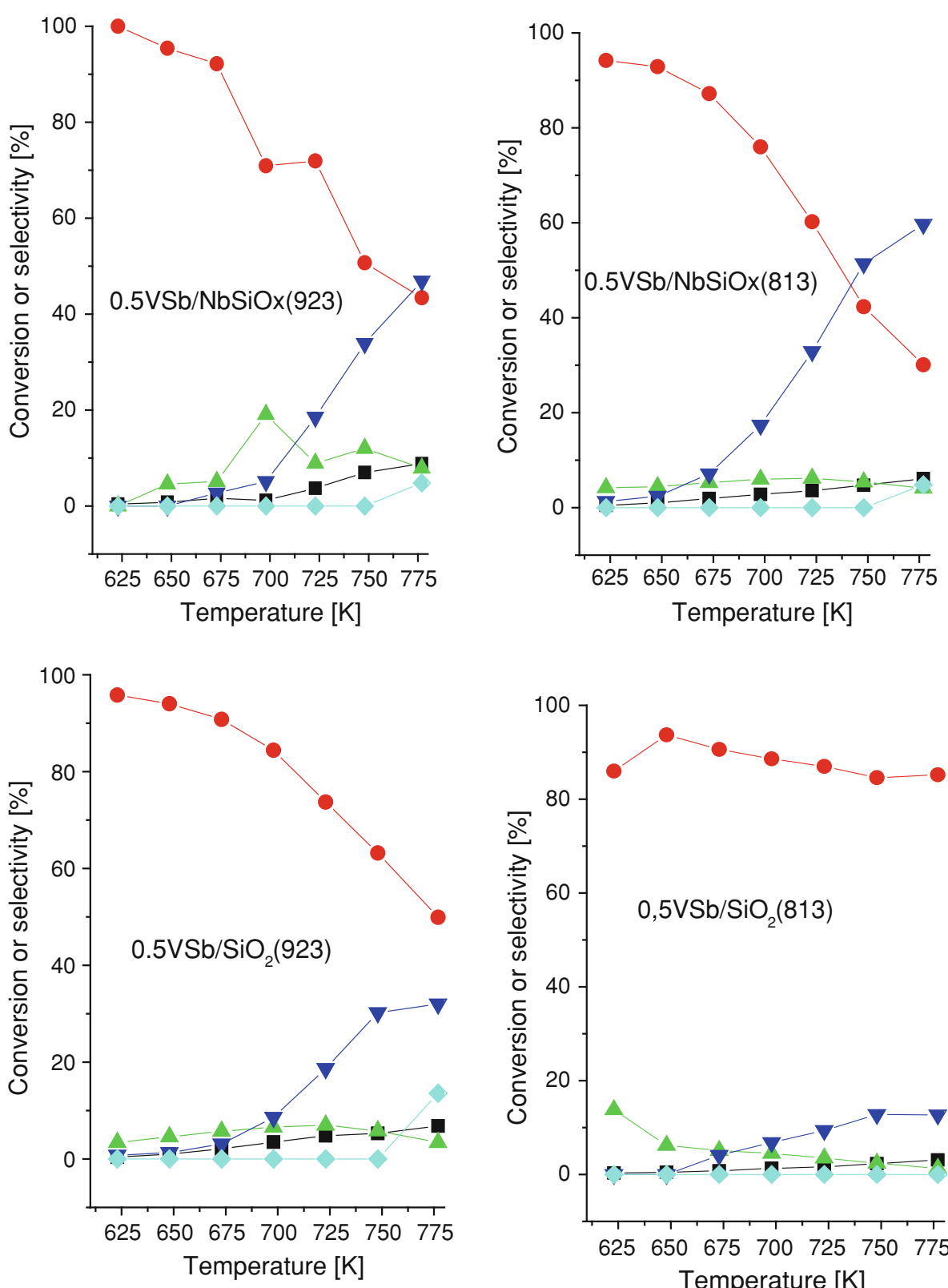

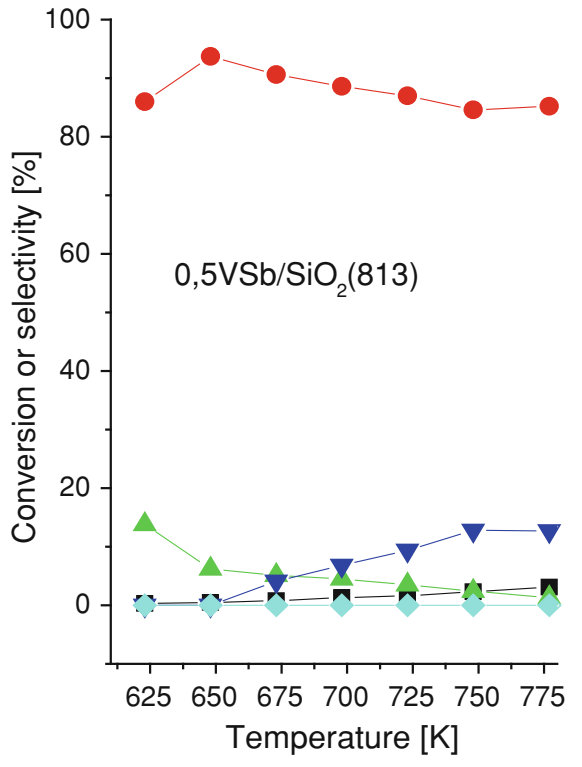

$\operatorname{NbSiOx}(813)$, since it presents $\mathrm{SbOx}$, the support is covered, and the $\mathrm{V}-\mathrm{Nb}-\mathrm{O}$ species documented by Raman spectra (Fig. 3).

\subsection{Role of V Species}

Vanadium species exhibit significantly different performance depending on their environment. They are efficient for propane ammoxidation when they are involved in the $\mathrm{SbVO}_{4}$ phase. Our results demonstrate that in the absence of excess antimony, it forms nanocrystalline $\mathrm{V}_{2} \mathrm{O}_{5}$ phase, which is determined by Raman spectroscopy (Fig. 3) and UV-Vis spectra (Fig. 2) (but is not large enough to generate an X-ray diffraction pattern (Fig. 1). This confirms that $\mathrm{V}_{2} \mathrm{O}_{5}$ is detrimental for acrylonitrile formation since it enhances the selectivity to cracking products, acetonitrile and acetaldehyde.

\subsection{Role of $\mathrm{Nb}$ Species}

Rutile $\mathrm{SbVO}_{4}$ phase has been identified on both supports series (XRD, Raman spectra and UV-Vis). The nature of vanadium-antimony oxide is modulated by the presence of niobium in the support, since $\mathrm{Nb}-\mathrm{V}-\mathrm{O}$ vibrations are identified by Raman spectroscopy (Fig. 3). In addition, the presence of $\mathrm{Nb}$ in the support leads to the formation of larger 
Fig. 6 Propane conversion (square) and selectivity to propene (circle), acetonitrile (triangle), acrylonitrile (inverted triangle) and acetaldehyde (diamond) for catalysts with $\mathrm{V} / \mathrm{Sb}=1$ (at various temperatures in the range $623-773 \mathrm{~K}$ )
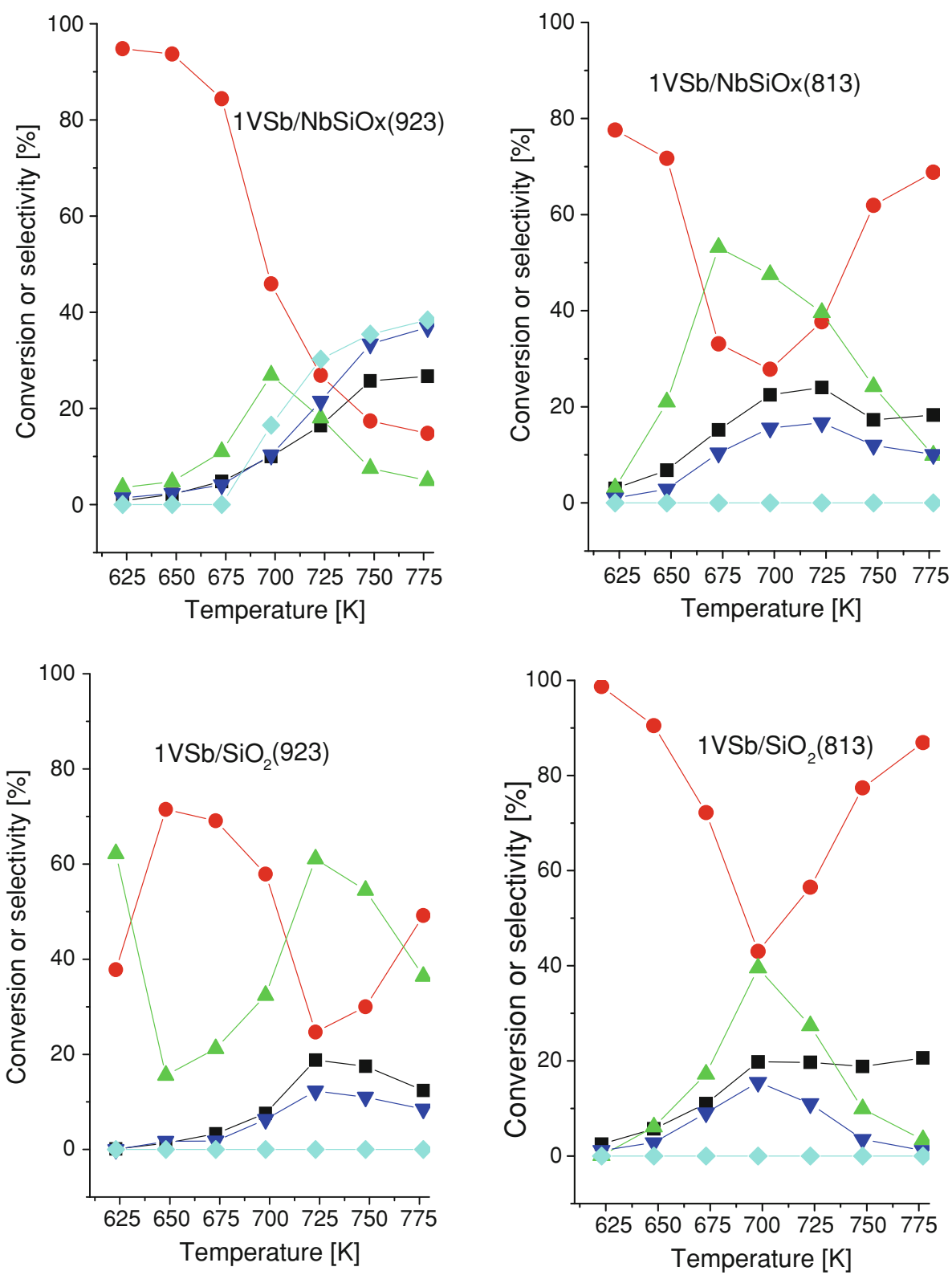

rutile particles (Table 1), especially for the samples calcined at the lowest temperature $(813 \mathrm{~K})$. $\mathrm{Nb}$ incorporation into the rutile lattice results in larger particles, with structural defects in the rutile structure, which enhances the catalytic properties of the rutile active phase (Fig. 4). This is in line with previous studies that have shown that the $\mathrm{SbVO}_{4}$ rutile structure stabilizes cation vacancies in its structure [12], and with the ability of $\mathrm{Nb}$ species to incorporate into the rutile lattice [27]. This leads to a higher structural reactivity that significantly enhances the catalytic properties of the rutile SbVOx active phase for propane ammoxidation.

Both, niobium promoting effect, and the higher dispersion of $\mathrm{SbVO}_{4}$ enhances the capability of the $\mathrm{SbVO}_{4}$ doped rutile structure to activation of the nitrile insertion into the propane molecule, increasing the selectivity to nitriles versus oxygenates for the catalysts with low loadings. At higher loadings, the amount of $\mathrm{Sb}$ is higher and it seems that the interactions $\mathrm{Sb}-\mathrm{Nb}-\mathrm{O}$ phases are possible, which are detrimental to the nitrile insertion, and the yield of propylene/oxygenates increases.

The niobium-containing support reported here enhances the yield to acrylonitrile maximizing the promoting effect of niobium (Fig. 4). Since the promoting effect of niobium additive is limited to low loadings, and typically is lost when well defined niobium-containing phases form, it is necessary to control the amount of $\mathrm{Nb}$ to be incorporated. 
Such a behavior has been described when $\mathrm{Nb}$ has been used as promoter for different catalytic systems [16] like ethane ammoxidation [28, 29]. $\mathrm{Nb}$ doping of $\mathrm{Sb}-\mathrm{V}-\mathrm{O}$ system should avoid the formation of mixed $\mathrm{Nb}-\mathrm{Sb}-\mathrm{O}$ phases, which are inert, and subsequently, detrimental for acrylonitrile formation $[15,27]$. Using the $\mathrm{Nb}$-containing support described here, the formation of such $\mathrm{Sb}-\mathrm{Nb}-\mathrm{O}$ is not detected since $\mathrm{Nb}$ mobility is minimized, being limited to a promoting effect on the rutile $\mathrm{SbVO}_{4}$ phase.

\section{Conclusions}

Niobium species have a strong effect on the molecular structure and catalytic performance of the rutile SbVOx phase. The Nb effect on the structure of catalysts is evident since $\mathrm{V}-\mathrm{O}-\mathrm{Nb}$ vibrations have been identified by Raman spectroscopy, and, in addition, larger rutile $\mathrm{SbVO}_{4}$ particle sizes are reported when $\mathrm{Nb}$ is incorporated on the support, indicative that $\mathrm{Nb}$ species are able to incorporate into the lattice structure, creating cation vacancies. By this manner, the $\mathrm{Nb}$ species incorporated into the support matrix cooperate with the vanadium species in the SbVOx phase increasing the performance of such a phase for the nitrile formation in the propane molecule. Since $\mathrm{Nb}$ is a common additive that improves the catalytic behavior of different catalytic systems, the mesoporous $\mathrm{Nb}$-containing support described in the present paper could be useful for other catalysts and/or catalytic processes.

Nonordered VSb/NbSiOx materials reveal higher activity and selectivity to acrylonitrile than VSb/NbMCM41 [17] in ammoxidation of propane. The different oxide phases $\left(\mathrm{SbVO}_{4}, \mathrm{NaSb}_{5} \mathrm{O}_{13}, \mathrm{SbVO}_{5}\right)$ were detected on ordered mesoporous NbMCM-41 support, whereas only the rutile $\mathrm{SbVO}_{4}$ was found on nonordered $\mathrm{NbSiOx}$. The presence of this last phase as the only one is responsible for the higher effectiveness of ammoxidation of propane on $\mathrm{VSb} / \mathrm{NbSiOx}$ studied in this work.

\begin{abstract}
Acknowledgments Hanna Golinska-Mazwa is indebted to COST action D36 (WG D36/0006/06) for financial support during her STSM stay at ICP-CSIC (Spain). The Polish Ministry of Science (Grant N N 204 016439), National Research Center in Cracow, Poland (Grant No 2011/01/B/ST5/00847) and the Spanish Ministry of Science and Innovation (Grant CTQ2008/02461/PPQ) are acknowledged for the financial support. E. Rojas and R. López-Medina thank CONACYT (Mexico) and MAEC-AECID (Spain), respectively, for their $\mathrm{PhD}$ fellowships.
\end{abstract}

Open Access This article is distributed under the terms of the Creative Commons Attribution License which permits any use, distribution, and reproduction in any medium, provided the original author(s) and the source are credited.

\section{References}

1. Park DW, Park BK, Park DK, Woo HC (2002) Appl Catal A Gen 223:215

2. Li KT, Shyu NS (1997) Ind Eng Chem Res 36:1480

3. Guerrero-Pérez MO, Janas J, Machej T, Haber J, Lewandowska AE, Fierro JLG, Bañares MA (2007) Appl Catal B Environ 71:85

4. Shishido T, Inoue A, Konishi T, Matsuura I, Takehira K (2000) Catal Lett 68:215

5. Ballarini N, Berry FJ, Cavani F, Cimini M, Ren X, Tamoni D, Trifirò F (2007) Catal Today 128:161

6. Guerrero-Pérez MO, Fierro JLG, Vicente MA, Bañares MA (2002) J Catal 206:339

7. Guerrero-Pérez MO, Fierro JLG, Vicente MA, Bañares MA (2007) Chem Mater 19:6621

8. Guerrero-Pérez MO, Bañares MA (2008) ChemSusChem 1:511

9. Calvino-Casilda V, Guerrero-Pérez MO, Bañares MA (2010) Appl Catal B Environ 95:192

10. Calvino-Casilda V, Guerrero-Pérez MO, Bañares MA (2009) Green Chem 11:939

11. Rojas E, Calatayud M, Guerrero-Pérez MO, Bañares MA (2010) Catal Today 158:178

12. Landa-Cánovas AR, García-García FJ, Hansen S (2010) Catal Today 158:156

13. Grasselli RK (1997) In: Ertl G, Knozinger H, Weitkamp J (eds) Handbook in catalysis, vol V. Wiley-VCH, Weinheim, pp 2302-2326

14. Grasselli RK (2003) Top Catal 23:5

15. Guerrero-Pérez MO, Fierro JLG, Bañares MA (2003) Phys Chem Chem Phys 5:4032

16. Guerrero-Pérez MO, Bañares MA (2009) Catal Today 142:245

17. Golinska H, Rojas E, López-Medina R, Calvino-Casilda V, Ziolek M, Bañares MA, Guerrero-Pérez MO (2010) Appl Catal A Gen 380:95

18. Golinska H, Decyk P, Ziolek M (2011) Catal Today 169:242

19. Carniti P, Gervasini A, Marzo M (2008) J Phys Chem C 112:14064

20. Roussel M, Bouchard M, Bordes-Richard E, Karim K, Al-Sayari S (2005) Catal Today 99:77

21. Atuchin VV, Kalabin IE, Kesler VG, Pervukhina NV (2005) J Electron Spectrosc Relat Phenom 142:129

22. López-Medina R, Fierro JLG, Guerrero-Pérez MO, Bañares MA (2010) Appl Catal A Gen 375(1):55

23. Trejda M, Tuel A, Kujawa J, Kilos B, Ziolek M (2008) Microporous Mesoporous Mater 110:271

24. Bañares MA, Wachs IE (2002) J Raman Spectrosc 33:359

25. Gao X, Wachs IE, Wong MS, Ying JY (2001) J Catal 203:18

26. Guerrero-Pérez MO, Peña MA, Fierro JLG, Bañares MA (2006) Ind Eng Chem Res 45:4537

27. Guerrero-Pérez MO, Martínez-Huerta MV, Fierro JLG, Bañares MA (2006) Appl Catal A Gen 298:1

28. Rojas E, Guerrero-Pérez MO, Bañares MA (2009) Catal Commun 10:1555

29. Guerrero-Pérez MO, Rojas E, Gutiérrez-Alejandre A, Ramírez J, Sánchez-Minero F, Fernández-Vargas C, Bañares MA (2011) Phys Chem Chem Phys 13:9260 